\title{
(In)visibilidad y resistencia. Ciudadanías clandestinas y activismo migrante transnacional
}

\author{
Daniel Córdoba González de Chávez *
}

\begin{abstract}
Resumen
Las migraciones, inscritas en las relaciones de poder, a menudo implican procesos de resistencia que pivotan alrededor de importantes asuntos sociales y políticos como son los derechos de ciudadanía, residencia o movilidad. Estas luchas se manifiestan en acciones contra centros de detención o por la despenalización de actividades de subsistencia. Conceptualizados como no ciudadanos por determinados discursos institucionales y mediáticos, los migrantes irregularizados mantienen una relación conflictiva con su propia (in)visibilidad, que se torna estratégica al materializarse en procesos de resistencia no exentos de riesgos y tensiones. Las luchas de los sanspapiers de finales de los noventa en Francia o las más recientes de los manteros en España dan buena cuenta de ello. En este contexto, la batalla por la ciudadanía trasciende el ámbito legal para buscar reconocimiento como sujeto político capaz de ejercer sus derechos sin necesidad de que le sean otorgados. Desde esta perspectiva, los migrantes indocumentados deben ser considerados como sujetos que, a través de la apropiación de prácticas de ciudadanía, visibilizan el papel que juegan dentro del mercado laboral y de las dinámicas de reproducción social. Estas ciudadanías migrantes demuestran que la ciudadanía no es solo un dispositivo de gobernanza, exclusión y diferenciación, sino que puede derivar en procesos de creación de identidades y modos de pertenencia, a la vez que ayudar a replantear y superar el marco del estado-nación como único posible para su administración.
\end{abstract}

\section{Palabras clave}

Migración; Autonomía; Ciudadanía; (In)visibilidad; Poscolonialidad.

\section{We}

TITLE

(In)visibility and resistance. Clandestine citizenships and transnational migrant activism
* Daniel CÓRDOBA GONZÁLEZ DE CHÁVEZ, Graduado en Geografía e Historia y estudiante de Máster en Historia, Relaciones Internacionales y Cooperación en la Universidade do Porto.

Recibido: 01/04/2018 Aceptado: $17 / 09 / 2018$

DOI:

https://doi. org/10.15366/relacionesinternacionales2018.39.011

\begin{abstract}
Migrations, as part of power relations, often involve resistance processes linked to important social and political issues such as citizenship, residence or movement rights. These struggles become apparent in acts against detention centres, claims for regularisation or campaigns for decriminalization of subsistence activities. Framed as non citizens, irregularized migrants keep a problematic relationship with their own (in)visibility, which becomes strategic when they get involved in resistance processes. The struggles of the sanspapiers in France in the late 90 s and the more recent of street sellers in Spain are good examples. In this context, struggles around citizenship go beyond legal considerations to be situated in the pursuit of recognition as a political subject able to exercise their rights even when they have not been granted them. Thus, undocumented migrants should be considered as subjects whose acts are able to render visible the role they play within the labour market and the very dynamics of social reproduction. This migrant citizenships show that citizenship is not just a governance, exclusion and differentiation device, but also that could be thought as a process leading to the creation of identities and different forms of belonging, while helping rethink and go beyond nation-state as the only framework to manage it.
\end{abstract}

\section{KEYWORDS}

Migration; Autonomy; Citizenship; (In)visibility; Post-coloniality. 


\section{ntroducción}

There exists an international citizenship which as such has its rights and duties, and which is obliged to stand up against all forms of abuse of power, no matter who commits them, no matter who are their victims. After all, we are all governed, and, by that fact, joined in solidarity.

Michel Foucault ${ }^{1}$

En los últimos años hemos asistido a un aumento excepcional del número de refugiados y solicitantes de asilo llegados a territorio europeo; el número total de solicitudes en 2014 fue 627000 y en 2015 fueron 1322 000. Si bien esta cifra se mantiene en 2016, con un número total de solicitudes cercano a 1300 000, en 2017 se produce un descenso hasta las 705 000 solicitudes. Del mismo modo, durante 2016 llegaron a la Unión Europea 2,4 millones de migrantes de países no miembros -terceros países, según la denominación oficial más común-y para el 1 de enero de 2017 el número de ciudadanos de terceros países residiendo en la UE era de 21,6 millones $^{2}$. Si a estos números sumamos las muertes de migrantes que tratan de llegar a Europa por el mar -y otras rutas- la imagen que obtenemos adquiere tintes más oscuros.

Sin embargo, más allá de la reciente crisis y del momentáneo foco mediático, la realidad nos indica que estos números forman parte de una tendencia que ha sido constante, al menos, desde el inicio de los noventa. Así, entre 1998 y 2017 el número de entradas no autorizadas por mar se eleva a $2367821^{3}$, mientras que entre 1993 y 2017 el número de muertos mientras intentaban alcanzar la UE se eleva a $33305^{4}$. Unas cantidades elevadas que están relacionadas con la herencia de la colonización y las consecuencias de los conflictos postcoloniales. ${ }^{5}$ que han configurado un mapa de relaciones geopolíticas asimétricas entre las excolonias y sus antiguas metrópolis. Encontramos un buen ejemplo en las relaciones entre Francia y Argelia, estudiadas por Abdelmalek Sayad ${ }^{6}$, que explica cómo el fracaso de los estados postcoloniales y su falta de autonomía han tenido importantes repercusiones sobre sus poblaciones y, como consecuencia, en los movimientos migratorios. En cualquier caso, si algo muestran estas cifras -las más recientes y las que muestran la tendencia de los últimos

1 Discurso originalmente pronunciado en lengua francesa el 19 de junio de 1981 en conferencia de prensa en Ginebra. Esta versión en inglés fue traducida por Colin Gordon y está disponible en https://www.opendemocracy. net/can-europe-make-it/michel-foucault/rights-and-duties-of-international-citizenship [Consultado el 10 de marzo de 2018]

2 Datos recuperados a partir de estadísticas de Eurostat. Aunque las estadísticas muestran datos de 2016, estos fueron recopilados en marzo de 2018. La próxima actualización será publicada en abril de 2019. Los datos relativos a solicitudes de asilo están disponibles en https://ec.europa.eu/eurostat/statistics-explained/index.php/Asylum_ statistics\#Number_of_asylum_applicants:_drop_in_2017 [Consultado el 19 de octubre de 2018]; mientras que aquellos relacionados con las estadísticas sobre migración y población migrante son accesibles en https:// ec.europa.eu/eurostat/statistics-explained/index.php/Migration_and_migrant_population_statistics\#Migration_ flows:_2_million_non-EU_immigrants [Consultado el 19 de octubre de 2018]

3 FARGUES, Philippe, Four Decades of Cross-Mediterranean Undocumented Migration to Europe, International Organization for Migration, IOM, Geneva, 2017, p. 9.

4 Son datos de la organización UNITED disponibles en http://www.unitedagainstracism.org/campaigns/annualcampaigns/fortress-europe/ [Consultado el 11 de marzo de 2018]

5 AVALLONE, Gennaro, "Migraciones y Relaciones de Poder En La Agricultura Global Contemporánea: Entre Actualidad y Ruptura de La Herencia Colonial" en Relaciones Internacionales 36, 2017, pp. 73-92, p. 82.

6 SAYAD, Abdelmalek, The suffering of the inmigrant, Cambridge, Polity, 2004, pp. 64 y 81. 
veinticinco años- es que la llamada "crisis de migración" nos habla de una crisis más profunda de Europa misma, como proyecto socio-político e institucional, algo que nos debería llevar a plantear una crítica postcolonial ${ }^{7}$ del gobierno de las migraciones en esta región del mundo ${ }^{8}$.

La multiplicación de fronteras y zonas de frontera9 ${ }^{9}$ alrededor y dentro del espacio europeo, de la que es partícipe no solo la propia UE $-\mathrm{y}$ diversas agencias destinadas al control migratorio- sino también los estados miembros, e incluso otros estados europeos y de la periferia europea que no son miembros de la UE, ha venido de la mano de un aumento de las luchas de frontera y ha contribuido a dar forma a lo que Sandro Mezzadra y New Keywords Collective ${ }^{10}$ han denominado la Europa Frontera, una Europa hecha de fronteras tanto exteriores como interiores, tanto físicas como simbólicas y que se alzan como barreras más o menos visibles a la libertad de movimiento y al reconocimiento del otro. Parece esta una metáfora que retrata la realidad espacial y política europea mejor que aquella de la Europa Fortaleza ${ }^{11}$, que si bien fue efectiva a la hora de plantear una crítica radical del régimen de frontera, no refleja adecuadamente la complejidad del marco institucional europeo, al mismo tiempo que asume que dentro de la fortaleza -el territorio europeo- existe una suerte de tregua que permite la libertad de movimiento tanto como la de permanencia.

Una de las múltiples fronteras con las que se encuentran los migrantes que ya consiguieron traspasar las fronteras geopolíticas e ingresar en la UE, es la ciudadanía europea ${ }^{12}$. Constituida como dispositivo para el gobierno de las migraciones, se sitúa en la base de un ejercicio biopolítico para la gestión de las poblaciones móviles, al permitir un gobierno de las migraciones funcional a los intereses de los estados y los mercados de trabajo por medio de un acceso diferenciado y estratificado a los derechos y a las posibilidades materiales subsistencia. De este modo, la geopolítica europea camina de la mano de la biopolítica ${ }^{13}$ en

7 El término postcolonial no alude tanto a una visión cronológica de un tiempo que ha superado el colonialismo, sino más bien a las consecuencias del pasado colonial en las relaciones de poder en general y en las migraciones en particular.

8 Una visión más amplia de la crisis de/en Europa, y de sus elementos constitutivos puede leerse en NEW KEYWORDS COLLECTIVE, «Europe/Crisis: New Keywords of "the Crisis" in and of "Europe"», Zone Books near futures, 2016, p. 45.

9 Al hablar de zonas de frontera no se hace referencia necesaria o únicamente a las fronteras geopolíticas que separan los estados-nación, sino también a espacios que adquieren una dimensión fronteriza, en tanto que forman parte del régimen que busca controlar, disciplinar y fragmentar a la población migrante.

${ }^{10}$ Se trata de un proyecto colaborativo que reúne a diversos autores dentro de los estudios críticos sobre migraciones, cuyo propósito es desarrollar un nexo entre términos y conceptos que atraviesan la problemática contemporánea de las migraciones. El concepto de "Europa Frontera" de Sandro Mezzadra aparece mencionado en la obra citada en la nota a pie de página 8.

${ }^{11}$ Son varios los autores que han desarrollado la crítica al concepto de Europa Fortaleza. Sirvan de ejemplo: RIGO, Enrica, "Citizens despite borders: Challenges to the territorial order of Europe", en SQUIRE, Vicky (ed.) The Contested Politics of Mobility: Borderzones and Irregularity, 2010, 199-215; BOJADŽIJEV, Manuela y KARAKAYALI, Serhat, «Recuperating the Sideshows of Capitalism: The Autonomy of Migration Today», E-flux, no 17, 2010, 1-9; o SCHEEL, Stephan, "Studying embodied encounters: autonomy of migration beyond its romanticization", Postcolonial Studies, 16, n० 3, 2013, 279-288.

12 Parece oportuno señalar, siguiendo a Joaquín Arango, la diferencia entre una ciudadanía formal que, generalmente, identificamos con la nacionalidad y que equivale a la posesión de derechos políticos como el derecho a voto; y una ciudadanía sustantiva que, aunque también se refiere la relación de los individuos con el estado, no tiene un carácter estrictamente jurídico y representa la posesión plena de derechos. En este texto nos referiremos a esta segunda acepción que nos permite referirnos al goce pleno de derechos sin hablar de naturalización. Ver ARANGO, Joaquín, "Derechos Sociales, Ciudadanía e Integración," en Inmigración y Derechos de Ciudadanía, ed. Gemma Pinyol, Barcelona, Fundación CIDOB, 2006.

${ }^{13}$ El concepto de biopolítica alude a la relación entre la política y la vida. Según Foucault la biopolítica se constituye en herramienta para el control de la sociedad a través del control de los cuerpos vivos de las personas que 
lo que respecta a las migraciones, lo que nos permite distinguir con Jennifer Hyndman un control biopolítico de las poblaciones y un control geopolítico de los territorios ${ }^{14}$.

Así pues, las migraciones están insertas en relaciones de poder que llevan aparejadas procesos de resistencia que pivotan alrededor de importantes asuntos sociales y políticos como son los derechos de ciudadanía, residencia o movilidad. Muchas de estas luchas por la libertad de movimiento se manifiestan en acciones contra centros de detención, por la regularización - la despenalización de actividades de subsistencia, aunque como veremos más adelante, otras adquieren formas más imperceptibles para adentrarse en lo que podríamos denominar espacios de resistencia cotidiana.

Conceptualizados como no ciudadano ${ }^{15}$ por buena parte de los discursos institucionales y mediáticos, los migrantes irregularizados mantienen una relación contradictoria y conflictiva con su propia visibilidad. Una relación que, como veremos más adelante, se torna estratégica, al materializarse en procesos de lucha y resistencia que no están exentos de riesgos y tensiones. Las luchas de los sanspapiers de finales de los noventa en Francia o las más recientes de los manteros ${ }^{16}$ en España dan buena cuenta de ello.

Este artículo pretende trazar algunas líneas que contribuyan a dibujar un mapa sobre las luchas migrantes poniendo el foco en la intersección entre los mecanismos de dominación -ciudadanía, régimen de fronteras, etc.- y las prácticas de contestación migrantes, articuladas a través de una relación estratégica con la (in)visibilidad, a veces impuesta - por los dispositivos de control del estado y el régimen de fronteras-, a veces elegida - por los propios migrantes en su empeño por sortear esos mismos dispositivos de control. Para ello, planteamos una mirada desde el enfoque de la autonomía de las migraciones - una forma de enfrentar el fenómeno de las migraciones que supone a la vez un programa de investigación y análisis, y una práctica activista - al tiempo que acudimos al trabajo de Michel Foucault para analizar el vínculo que une el poder, en tanto que gobierno de las poblaciones, con los procesos de resistencia. Esta mirada teórica, tendrá su correlato en el retrato de diversas experiencias que, sin ser exhaustivas o concluyentes, sí pretenden señalar el interés de un marco para el análisis de las prácticas políticas migrantes basado en la relación conflictiva que muchos migrantes mantienen con la ciudadanía como dispositivo de control y horizonte de derechos y el papel estratégico que la (in)visibilidad juega en sus luchas.

En el primer apartado realizaré algunas aclaraciones metodológicas y conceptuales

la componen. Ver FOUCAULT, Michel, Defender La Sociedad. Curso En El College de France (1975-1976), ed. Françoise Ewald y Alessandro Fontana, Fondo de Cultura Económica, México DF, 2000. Especialmente la Clase del 17 de marzo de 1976, a partir de la página 217.

${ }^{14}$ HYNDMAN, Jennifer, "The geopolitics of migration and mobility", Geopolitics 17, no 2, 2012, pp. 243-55.

15 Según Sayad, ser excluido del orden político es estar privado del derecho más fundamental, el derecho nacional, que, a su vez, comporta el derecho a tener derechos, a ser reconocido como miembro del cuerpo político. Ver SAYAD, Abdelmalek, "Estado, Nación e Inmigración. El Orden Nacional Ante El Desafío de La Inmigración", Apuntes de Investigación Del CECYP, 2008, pp. 101-16, p. 105.

${ }_{16}$ Vendedores ambulantes, o manteros, denominados así en las principales ciudades españolas, cuya actividad es perseguida por la ley al carecer de licencia y/o vender copias que atentan contra los derechos de propiedad. Se trata, en la mayoría de los casos, de la única actividad de subsistencia que pueden llevar a cabo en la situación de irregularidad en la que se encuentran muchos migrantes. Su nombre viene de la manta que usan estos vendedores para mostrar sus productos, facilitando la huida con toda la mercancía en caso de aparecer la policía. 
sobre el objeto de estudio; el segundo apartado propone un encuadre conceptual, esbozando las características más significativas que implica un análisis de fenómenos tales como la (in)visibilidad, la ciudadanía o las dinámicas de poder/resistencia; mientras que el último apartado fija la mirada sobre procesos específicos de lucha migrante, tanto aquellos que se producen en un espacio visible, como aquellas prácticas más imperceptibles que no solo escapan a las políticas de control, sino también, a menudo a la mirada de la sociedad.

\section{Algunos supuestos y aclaraciones}

En primer lugar, es importante señalar que la atención del artículo se centra en migrantes irregulares o aquellos que, aún teniendo algún tipo de permiso de trabajo, están insertos en el mercado informal de trabajo y, por lo tanto, con condiciones de vida muy precarizadas y con una absoluta carencia de los derechos sociales asociados a la ciudadanía y/o a la inserción en el mercado de trabajo. Son personas en una situación de vulnerabilidad que bien podría quedar recogida en el concepto de "nuda vida" de Giorgio Agamben ${ }^{17}$, aunque desprovisto de la carga de fatalidad que tiende a retratar a los migrantes como objetos de represión y arbitrariedades y no como sujetos con capacidad de agencia y de expresión de subjetividades políticas propias.

Aún siendo conscientes de que la barrera que separa regularidad de irregularidad constituye un factor determinante de las condiciones normativas y prácticas en el ejercicio de derechos y libertades ${ }^{18}$, me referiré mayormente a los migrantes ${ }^{19}$ de forma genérica, ya que considero que las líneas que separan a los migrantes legales de los irregulares o los solicitantes de asilo es muy delgada o difusa. Así, la diferencia entre ciudadanos y no ciudadanos no es dicotómica, sino que se asienta en una gradación continua y reversible. ${ }^{20}$. Por poner un ejemplo, cuando un solicitante de asilo llegado a Europa ve denegada su solicitud, se convierte automáticamente en un inmigrante irregular; del mismo modo que un nacional de tercer país que supera el periodo de estancia concedido en su visa pasa a ser considerado como un ilegal21. Del mismo modo, la política migratoria, en lo relacionado con los permisos de residencia, está fuertemente laboralizada -lo que, en la práctica, implica la subordinación del fenómeno migratorio a las necesidades del mercado laboral-. Para muchas personas migrantes, la posibilidad de permanencia legal siempre dependerá de la pervivencia del vínculo laboral, por lo que la amenaza de expulsión siempre estará presente ${ }^{22}$. De hecho, es frecuente encontrar migrantes con permiso de residencia temporal que, ante la dificultad

17 AGAMBEN, Giorgio, Homo Sacer. El Poder Soberano y La Nuda Vida I, Valencia, Pre-Textos, 1998.

${ }^{18}$ APARICIO, Marco, "Los Derechos Sociales de Las Personas Inmigradas En España", Revista de Estudios SocioJurídicos, 9, 2007, pp. 54-74, p. 72.

19 Prefiero el uso del término migrante puesto que incluye las dos realidades asociadas a los movimientos migratorios, la de aquellas personas que salen de un territorio -emigrantes- y la de aquellas otras que llegan para establecerse en un nuevo lugar -inmigrantes-.

${ }^{20}$ CHAUVIN, Sébastien y GARCÉS-MASCAREÑAS, Blanca, "Beyond Informal Citizenship: The New Moral Economy of Migrant Illegality," International Political Sociology 6, no 3, 2012, pp. 241-59, p. 242.

${ }^{21}$ El uso del término ilegal en cursiva implica un cierto rechazo al mismo, en primer lugar, por parte de los propios migrantes. Por otro lado, la consideración de ilegal para una persona conlleva graves problemas, pues como señalan algunos expertos en leyes, si un inmigrante no consigue la consideración de legalidad bajo legislaciones nacionales, pasaría a ser sujeto de la ley internacional, algo que tiene difícil aplicación práctica. Es por ello que, en general, prefiero el término irregular. Del mismo modo, en tanto que la irregularidad, como vemos, es producida y puesto que los propios migrantes tienden a no identificarse con esa irregularidad, intentaré hablar en este artículo de migrantes irregularizados.

22 APARICIO, Marco, "Los derechos sociales...", op.cit, p. 71. 
de conservar un contrato de trabajo, se ven abocados al trabajo informal.

Todo lo anterior sugiere que el estatus legal no siempre es tan claro como parece, siendo que en muchas ocasiones las personas migrantes no son simplemente regulares o irregulares, sino que es frecuente encontrar una mezcla de aspectos regulares e irregulares o una compleja gradación entre ambos, lo que, a su vez, indica la existencia de un espacio para diferentes formas de ambivalencia legal ${ }^{23}$ que lleva a algunos autores a hablar de semi legalidad. ${ }^{24}$ o ciudadanía precaria. ${ }^{25}$. Muy a menudo, el vocabulario de las Relaciones Internacionales se acepta acríticamente como algo dado y no problemático -términos como inmigrante ilegal son empleados en la literatura académica con frecuencia de forma acríticacuando la realidad es que los conceptos subyacentes a estos términos ayudan a configurar una visión muy determinada de los fenómenos que analizan, con frecuencia representaciones distorsionadas de una realidad construida como si fuese natural26.

En este sentido, resulta muy significativo el hecho de que el concepto de inmigración irregular como categoría analítica implica ciertas dificultades prácticas, puesto que, en última instancia, se trata de un epifenómeno de las migraciones y las políticas de ciudadanía ${ }^{27}$. La inmigración irregular es, por lo tanto, producida; es decir, sin políticas de inmigración no existiría la "ilegalidad", por lo que la misma definición de inmigración ilegal o irregular cambia dependiendo de la naturaleza de las políticas migratorias. De esta manera, los migrantes, como se decía más arriba, no son irregulares sino irregularizados por la ley.

Hablar de la producción de ilegalidad como un fenómeno derivado de las políticas migratorias y de ciudadanía, nos lleva a revisar el concepto de clandestinidad. Común en el imaginario colectivo popular, según Maja Sager, el concepto de clandestinidad o de migrantes clandestinos ${ }^{28}$ se refiere a la exclusión sufrida por los migrantes en varios niveles, a través de la interacción entre políticas migratorias, laborales y de integración -producción de ilegalidadque regulan sus derechos sociales, así como sus prácticas individuales y colectivas dentro de la sociedad civil y los movimientos sociales de protesta. Sin negar la validez del planteamiento de Sager, prefiero darle la vuelta, para plantear que las prácticas derivadas de la ilegalización dan lugar a lo que podríamos definir - aún a riesgo de caer en un oxímoron- como "ciudadanía clandestina"29, una ciudadanía no formal que se ejerce en la práctica cotidiana, fuera del

23 DÜVELL, Franck, "Paths into Irregularity: The Legal and Political Construction of Irregular Migration," European Journal of Migration and Law 13, nº 3, 2011, 275-95, p. 292.

${ }^{24}$ KUBAL, Agnieszka, "Conceptualizing Semi-Legality in Migration Research," Law and Society Review 47, no 3, 2013, 555-87, p. 567.

${ }^{25}$ LORI, Noora, "Statelessness, 'In-Between' Statuses, and Precarious Citizenship" EnThe Oxford handbook of citizenship, Ed. SHACHAR, Ayelet, et al., Oxford University Press, 2017. pp. 743-767 p. 744.

${ }^{26}$ HYNDMAN, Jennifer, op.cit, p.244; ECHEVERRÍA, .Gabriel, "Living at the Margins of State: Ecuadorian Irregular Migrants in Amsterdam and Madrid", Tesis doctoral, Universidad Complutense de Madrid, 2016, p.36.

27 Sobreestetema, puedeconsultarse SAMERS, Michael «An Emerging Geopolitics of 'Illegal' Immigration in the European Union», European Journal of Migration and Law, n०6, 2004, 27-45, p.28.

28 SAGER, Maja, Everyday Clandestinity: Experiences on the Margins of Citizenship and Migration Policies, Lund University, Lund, 2011, pp.20-21.

${ }^{29}$ EnricaRigo habla, en la misma línea, de "ciudadanía ilegal". Ver RIGO, Enrica, «Citizensdespiteborders...» op.cit., pp. 199-200. Sin embargo, opto por este concepto y no el de "ciudadanía ilegal" de Rigo, puesto que el término "ilegal" hace referencia a un estatus legal y parece indicar únicamente una exclusión de la ciudadanía formal. La ciudadanía clandestina no solo hace referencia a la exclusión, sino también a las prácticas ciudadanas que, desde la irregularidad, llevan a cabo muchos migrantes. 
marco legal y normativo y en la que podemos incluir a los manteros, esos vendedores callejeros insertos en una lógica desregulada del mercado laboral que ponen en práctica estrategias de supervivencia que van de la mano de dinámicas de acción colectiva. El rasgo más significativo de estas ciudadanías clandestinas sería el de demostrar que la ciudadanía no funciona únicamente como dispositivo de gobernanza, exclusión y diferenciación, sino que puede generar procesos de creación de nuevas identidades y modos de pertenencia, a la vez que obligar a replantear y superar el marco del Estado-nación -a través de la adquisición de la nacionalidad-como único posible para la administración de la ciudadanía.

\section{Migración, autonomía y resistencias}

La autonomía de las migraciones, como apuntábamos en la introducción, constituye a la vez un marco teórico y un proyecto político que conecta la investigación académica con las prácticas activistas. Uno de sus objetivos principales es dotar a la investigación y al activismo de marcos interpretativos alternativos a los dominantes -que muy a menudo basculan entre el humanitarismo y la securitización ${ }^{30}$. En su génesis está comprender las migraciones como un movimiento social y político en sí mismo y no únicamente como una respuesta a condicionantes estructurales económicos o sociales, lo que no quiere decir que las migraciones estén aisladas de las estructuras sociales, económicas y culturales, sino que se constituyen como una fuerza creativa dentro de estas estructuras ${ }^{31}$.

Bajo esta aproximación, los procesos de movilidad humana tienen la capacidad de transformar y producir realidades, situando al migrante como agente potencial de transformación política. Así, la autonomía de las migraciones rechaza tanto los discursos que retratan a los migrantes como víctimas, como los discursos securitarios que criminalizan la migración ${ }^{32}$ y sitúan a los migrantes como potenciales amenazas ${ }^{33}$, intentando, así, privilegiar la voz y la subjetividad de los migrantes. En cualquier caso, pese a las críticas que afirman que la autonomía de las migraciones tiende a una romantización de la movilidad humana y del nomadismo ${ }^{34}$, la mayor parte de autores que participan de este enfoque reconoce las duras condiciones en las que la migración se produce, únicamente se afirma que no solo responde a ellas; por el contrario, contribuye a crear las condiciones de posibilidad que permiten a los migrantes llevar a cabo sus prácticas de movilidad y permanencia por encima de los dispositivos de control ${ }^{35}$.

30 Ver NYERS, Peter, «Migrant Citizenships and Autonomous Mobilities», Migration, Mobility, \& Displacement 1, no 1,2015, p. 26.

31 PAPADOPOULOS, Dimitris, STEPHENSON, Niamh, y TSIANOS, Vassilis, Escape Routes: Control and Subversion in the 21st Century, London, Pluto Press, 2008, pp. 202-203.

32 Son discursos académicos que tienen su correlato en la racionalidad legal-institucional, influyendo frecuentemente en las políticas migratorias. Un ejemplo que trata de hacer converger ambas visiones - securitaria y humanitariapuede leerse de la mano de Gemma Pinyol-Jimenez, quien fue directora del Gabinete de la Secretaría de Estado de Inmigración y Emigración entre 2010 y 2012: PINYOL-JIMÉNEZ, .Gemma, "TheMigration-Security Nexus in Short: Instruments and Actions in theEuropeanUnion," AmsterdamLawForum 4, n 1, 2011, pp.36-57.

33 Entre los primeros autores en transformar las migraciones en un problema de seguridad encontramos a WEINER, Myron. "Security, Stability, and International Migration", International Security, vol. 17, no 3, 1992, pp. 91126; HUNTINGTON, Samuel P. "The Clash of Civilizations?", Foreign Affairs, vol. 72, no 3, 1993, pp. 22-49; o másrecientemente, FUKUYAMA, Francis. "Identity, immigration, and liberal democracy", Journal of democracy, vol. 17,n² 2, 2006, pp. 5-20.

34 Para un debate a cerca de las críticas a la autonomía de las migraciones ver SCHEEL, Stephan, "Autonomy of Migration Despite Its Securitisation? Facing the Terms and Conditions of Biometric Rebordering," Millennium: Journal of International Studies 41, no 3, 2013, pp. 575-600.

35 PAPADOPOULOS, Dimitris y TSIANOS, Vassilis S., «After citizenship: Autonomy of migration, organisational 
Desde esta perspectiva, la migración es autónoma, lo que implica que la movilidad humana precede y excede a la voluntad de control del poder soberano y los intereses en la captación de mano de obra migrante en condiciones ventajosas del capital global. De nuevo, esto no quiere decir que las migraciones no se vean afectadas por los dispositivos y las técnicas de control y vigilancia. Es innegable que los controles de frontera son cada vez más restrictivos y las tecnologías de vigilancia más sofisticadas, pero esto no impide las migraciones, únicamente las convierte en más peligrosas hasta el punto que en las últimas décadas se cuentan por miles las muertes de migrantes que intentaban ingresar por diferentes medios en territorio europeo.

\section{1. (In)visibilidad como paradoja del sujeto migrante}

Cuando se habla de la multiplicación de fronteras y zonas de frontera es importante señalar que muchas de estas no coinciden necesariamente con las fronteras físicas que separan a los estados-nación, sino que son fronteras internas que pasan normalmente inadvertidas. Son de alguna manera, fronteras invisibles, una de cuyas características principales es precisamente que funcionan como dispositivos de invisibilización de las personas migrantes irregularizadas. En este sentido, (la falta de) visibilidad se convierte en una barrera para la búsqueda de mejores condiciones de acceso a los servicios sociales o mayores posibilidades de conseguir un estatus legal o la ciudadanía. En los estudios poscoloniales, la visibilidad está asociada al empoderamiento y las posibilidades de promoción social, mientras que la invisibilidad se relaciona con la falta de conocimiento, jugando, por lo tanto, un papel crucial en el mantenimiento del estatus quo. De acuerdo con Francisco Villegas ${ }^{36}$, "[v]isibility and invisibility operate through a variety of markers including race, gender, sexuality, ability, and immigration status. [...] These markers serve to legitimize and delegitimize the daily experiences of individuals as unimportant or socially irrelevant", influyendo decisivamente en sus posibilidades de reconocimiento por parte de otros actores sociales.

Los procesos de representación, ya sea en inmigrantes o cualquier otro sujeto social, se articulan a través del reconocimiento social. Si queremos tratar el reconocimiento con un mínimo de rigor analítico, primero debemos determinar cuál es el papel de la visibilidad tanto en su consecución, como en la acción gubernamental. Para ello, resulta interesante rescatar la noción de visibilidad de Andrea Brighenti ${ }^{37}$, quien distingue tres tipos de (in)visibilidad. Primero, un tipo social que está relacionada con el reconocimiento, es decir, la lucha por ser visto, lo que implica una reclamación sobre su identidad. En segundo lugar, la visibilidad de tipo mediático, aunque puede interactuar con el primer tipo, tiende a retratar a los sujetos aislados de su contexto original, proyectándolos hacia otro diferente, con su propia lógica y reglas, por lo que los sujetos pierden capacidad de proyectar la imagen que desean transmitir. Finalmente, existe una visibilidad de control, que funciona como una forma de regulación del cuerpo social en un modo similar al propuesto por Foucault en su obra Vigilar y Castigar.

Estos tres tipos de visibilidad operan de formas diferentes $y$, a veces, incluso

ontology and mobile commons», Citizenship Studies 17, no 2, 2013, pp. 178-196, p. 184.

36 VILLEGAS, Francisco J., «CHAPTER SEVEN : Strategic In / Visibility and Undocumented Migrants», Counterpoints, no 368, 2010, 147-170, pp.149-150.

${ }^{37}$ BRIGHENTI, Andrea, «Visibility», Current Sociology 55, no 3, 2007, pp. 323-342, p.339. Brighenti cita aquí FOUCAULT, .Michel, Vigilar y Castigar. Nacimiento de La Prisión, Buenos Aires, Siglo XXI, 2002. 
contradictorias. Mientras que el último de ellos pretende imponer formas muy específicas de visibilidad sobre los migrantes, lo que resulta, muy a menudo, en detenciones y deportaciones; el segundo tipo crea una distorsión en la imagen percibida sobre ellos; y el primero los aísla del cuerpo social, convirtiéndolos en sujetos invisibles. Los tres tipos tienen un fuerte impacto en los migrantes y, en algunos aspectos están muy relacionados; entre ellos se establece una tensión dialéctica que se torna estratégica cuando las personas migrantes ponen en marcha prácticas políticas y de resistencia y que constituye un elemento central en el ejercicio de una ciudadanía que les es negada con demasiada frecuencia.

\section{2. ¿Ciudadanía? Una mirada desde la autonomía de las migraciones}

En la cita que da inicio a este artículo, Foucault habla de una ciudadanía internacional, no sujeta por el estado-nación sino por una comunidad de "gobernados" unidos por vínculos de solidaridad ${ }^{38}$. Las prácticas políticas y las luchas de los migrantes dan forma a un movimiento social en si mismo -aún si no responden siempre a una lógica organizada y movimentistapuesto que su lucha política desborda $y$, en cierta medida, contribuye a deconstruir la noción dominante de ciudadanía liberal en tanto que un estatus adquirido y un modo de pertenencia basado en la nacionalidad ${ }^{39}$. Quizá por ello estas luchas y prácticas políticas no estén muy lejos de la ciudadanía internacional que planteaba Foucault. Colin Gordon sugiere que esta noción de ciudadanía internacional vendría a ser una suerte de "contra-ciudadanía" o ciudadanía suplementaria ${ }^{40}$; sin embargo para el caso que nos ocupa prefiero el término de ciudadanías clandestinas, al que se aludía más arriba, como reflejo de un modelo en contradicción permanente con la visión normativa dominante que, lejos de estar en crisis, sigue funcionando tanto como vehículo de integración como de exclusión o diferenciación ${ }^{41}$.

El concepto normativo de ciudadanía en el estado moderno tiene, según Seyla Benhabib ${ }^{42}$, tres componentes: la identidad colectiva determinada por el sentido de pertenencia a una entidad nacional; la membresía al estado-nación que trae consigo la adquisición de derechos políticos; y el acceso al estado del bienestar y los derechos sociales. Sin embargo, esta misma visión de la ciudadanía construye un muro que aísla a los migrantes irregularizados de los derechos sociales y políticos. Siguiendo a Papadopoulos y Tsianos ${ }^{43}-y$ otros autores desde la autonomía de las migraciones- frontera y ciudadanía, son las dos caras de una misma moneda que funcionan, no tanto como forma de exclusión o de bloqueo de la migración,

\footnotetext{
${ }^{38}$ Discurso originalmente pronunciado en lengua francesa el 19 de junio de 1981 en conferencia de prensa en Ginebra. Esta versión en inglés fue traducida por Colin Gordon y está disponible en https://www.opendemocracy. net/can-europe-make-it/michel-foucault/rights-and-duties-of-international-citizenship [Consultado el 10 de marzo de 2018]

${ }^{39}$ Son varios los autores que subrayan este efecto de las luchas migrantes, baste citar a TURNER, Joe, "(En) genderingthepolitical: Citizenshipfrom marginal spaces", CitizenshipStudies 20, no 2, 2016, 141-55; O VARELA, Amarela, "La ciudadanía instituida en la era de la resistencia: el movimiento migrante en Barcelona como agente de nuevos dircusos", en BOLAÑOS, Bernardo (ed.), Biopolítica y Migración. El eslabón perdido de la globalización, Ediciones Acapulco, México DF, 2015.

${ }^{40}$ GORDON, Colin, The drowned and the saved: Foucault's texts on migration and solidarity, Open Democracy, 2015: https://www.opendemocracy.net/can-europe-make-it/colin-gordon/drowned-and-saved-foucaults-textson-migration-and-solidarity [Consultado el 14 de marzo de 2018]

${ }^{41}$ SUAREZ, Liliana, "Ciudadanía y Migración: ¿un oximorón?", Revista de Migración, Puntos de Vista, no 4, 2005 , p.37.

42 BENHABIB, Seyla, "Borders, Boundaries, and Citizenship", Political Science \& Politics 38, no 4, 2005, 673-677, p. 675.

43 PAPADOPOULOS, Dimitris y TSIANOS, Vassilis S., «After citizenship...», op.cit., pp. 181-182.
} 
sino como un mecanismo de institucionalización de la velocidad y la magnitud de los flujos. Frontera y ciudadanía crean un espacio de producción de ilegalidad que está en la base del dispositivo biopolítico ${ }^{44}$ de gobierno de las migraciones: mientras unos migrantes son representados como legales y deseados por el estado y los discursos institucionales, otros se convierten en ilegales.

Esta forma de integración diferencial supone una intensificación de la ciudadanía como tecnología de gobierno que describe cómo la integración puede implicar diferentes niveles de subordinación y ser instrumental para la necesidad del poder soberano de integrar mercado de trabajo, movilidad y seguridad, garantizando una relación fluida entre las prácticas de gobierno, los intereses del capital y los deseos de los migrantes. Así pues, desde el enfoque autonomista la ciudadanía se plantea como un corte que opera en el eje que se sitúa entre las posibilidades de representación y el acceso a los derechos. El poder soberano, guiado por las coyunturas, tiende a desplazar este corte hacia el extremo de la invisibilidad y la ilegalidad, produciendo un acceso diferenciado, fragmentario y estratificado a los derechos ${ }^{45}$; cuando esto sucede, la única posibilidad que le queda a los colectivos migrantes es la movilización, convertida en el único horizonte de presión al poder soberano hacia la consecución de derechos, siendo esta la forma en la que la ciudadanía se extiende ${ }^{46}$.

En contraste, otras visiones apuntan a una dimensión de contestación de la ciudadanía que, a través de su ejercicio práctico sin necesidad de la concesión legal del estatuto, es capaz de generar subjetividades propias ${ }^{47}$. En este sentido, resulta conveniente acercarnos a la ciudadanía reconociendo su doble dimensión: como dispositivo de exclusión y como espacio de contestación y resistencia que alumbra la ciudadanía clandestina a la que nos venimos refiriendo. Esta doble dimensión de la ciudadanía supone una paradoja para los movimientos migrantes, en tanto que muro y espacio de lucha: es al mismo tiempo el objetivo de muchos activistas migrantes, así como el régimen de exclusión contra el que protestan ${ }^{48}$.

Es precisamente esta doble condición de la ciudadanía, la que empuja a algunos autores referirse al concepto de ambivalencia como uno de los elementos centrales de las luchas migrantes. Vicky Squire ${ }^{49}$ y Sandro Mezzadra ${ }^{50}$ hablan de la irregularidad como una condición ambigua o ambivalente, al permitir procesos de (re)apropiación desarrollados mediante diferentes acciones de protesta o actos de ciudadanía, frecuentemente llevados

${ }^{44}$ La gubernamentalidad de las poblaciones basada en el biopoder, el gobierno de la vida, se compone de un complejo sistema de dispositivos de control que construye y sostiene imaginarios sociales que nombran la pertenencia política en clave de "derechos" y "garantías" y la encuadran en la noción de ciudadanía.

${ }^{45}$ Ver NYERS, Peter, "Migrant Citizenshipp...", op.cit., p.24; o PAPADOPOULOS, Dimitris y TSIANOS, Vassilis S., "After citizenship"

46 SUÁREZ-NAVAZ, Liliana, "Introducción. La lucha de los sin papeles. Anomalías democráticas y la (imparable) extensión de la ciudadanía", en Las luchas de los sin papeles y la extension de la ciudadania. Perspectivas críticas desde Europa y Estados Unidos., ed. Liliana Suarez, Raquel Macia-Pareja, y Ángela Moreno García, Traficantes de Sueños, 2007, pp. 185-213.

47 MEZZADRA, Sandro, "Capitalismo, migraciones y luchas sociales: La mirada de la autonomía", Nueva Sociedad no 237, 2012, 159-178, p. 160.

48 TYLER, Imogen y MARCINIAK, Katarzyna, "Immigrant protest: An introduction", Citizenship Studies 17, no 2, 2013, 143-156, p.153.

49 SQUIRE, Vicki, «The Contested Politics of Mobility: Politicizing Mobility, Mobilizing Politics» en SQUIRE, Vicki, (ed.), The Contested Politics of Mobility: Borderzonesand Irregularity, Routledge, 2010, p. 11.

${ }^{50}$ MEZZADRA, Sandro, «Capitalismo, migraciones...», op.cit., p.162. 
a cabo desde esa "clandestinidad" a la que empuja la irregularidad. De manera similar, Kim Rygiel ${ }^{51}$ analiza la ciudadanía, al mismo tiempo, como un régimen global de control de la movilidad migrante y como una forma de contestación y resistencia de este mismo régimen.

Enlazando con la idea clásica de Foucault que concibe los procesos de resistencia como parte inherente a las relaciones de poder, se podrían poner en cuestión aquellas visiones que, desde la autonomía de las migraciones, declaran una primacía absoluta de las dinámicas de movilidad migrante sobre el control soberano, representado por el régimen de frontera y las acciones de los estados-nación. Anne McNevim ${ }^{52}$, por ejemplo, usa el concepto de ambivalencia para referirse a la tensión que se produce, en el contexto de las luchas migrantes, entre aquellos que buscan ver reconocidos sus derechos -intengrándose a una ciudadanía más normativa - y los que pretenden escapar a los discursos del poder soberano - ejerciendo en la práctica una suerte de ciudadanía clandestina-.

Irregularidad y ciudadanía, control y movilidad constituyen, así, un territorio ambivalente y en disputa, con un importante potencial transformador, en el que diferentes formas de contestación y resistencia migrante se mantienen en pugna permanente con los dispositivos de dominación del poder soberano, desafiando el nexo soberanía-ciudadaníaterritorio. Un espacio de lucha constituido a partes iguales por irregularidad y ciudadanía y mediado por esa forma de acción política que definida como ciudadanías clandestinas.

\subsection{Poder (soberano), resistencia (migrante) y antagonismo biopolítico}

Uno de los atributos del poder soberano está relacionado con su capacidad de ejercer un dominio absoluto sobre el derecho de la vida y la muerte ${ }^{53}$. Foucault retrató el cambio que se produjo entre las tradicionales sociedades disciplinarias - aquellas que ejercen su poder sobre el cuerpo- y las formas modernas de dominación cuyo poder se orienta a la propia vida de los seres humanos - biopoder. Este tránsito vino a completar "el viejo derecho de soberanía - hacer morir o dejar vivir - con un nuevo derecho, que no borraría el primero pero lo penetraría, lo atravesaría, lo modificaría y sería un derecho o, mejor, un poder exactamente inverso: poder de hacer vivir y dejar morir"54. En el apartado anterior hemos visto cómo, por un lado, la ciudadanía, aunque de una forma diferenciadora y estratificadora, se constituye como un sistema de inclusión - hacer vivir- mientras que, por otro, contiene discursos que la configuran como un dispositivo de exclusión que invisibiliza y niega a los "otros" el derecho a permanecer y pertenecer - dejar morir-.

${ }^{51}$ De su obra de 2011 Globalizing Citizenship, referenciada en NYERS, Peter, «Migrant Citizenshipp...», op.cit., p. 33.

52 Aquí puede leerse una crítica a lo que la autora denomina las visiones más reduccionistas de la autonomía de las migraciones, McNEVIN, Anne, "Ambivalence and citizenship: Theorisingthepoliticalclaims of irregular migrants", Millennium: Journal of International Studies 41, n० 2, 2013, pp. 182-200.

${ }^{53}$ Aunque parezca una afirmación atrevida, así fue, sin duda, en las tradicionales sociedades disciplinarias y así es incluso en las modernas democracias representativas cuando legislan y/o regulan sobre la eutanasia, el derecho al aborto $y$, en algunos casos de forma más directa cuando instituyen la pena de muerte. Agamben, hablando sobre la definición legal de la muerte cerebral, afirma que científicos afines al régimen nazi no "habían ido nunca tan lejos en el camino de la politización de la nuda vida; pero (signo evidente de que la biopolítica moderna ha traspasado un nuevo umbral) en las democracias modernas es posible decir lo que los biopolíticos nazis no se atrevían a decir". En AGAMBEN, Giorgio, "Homo Sacer...", op.cit., pp.209-210.

${ }^{54}$ FOUCAULT, Michel, Defender la sociedad. Curso en el College de France (1975-1976), ed. Françoise Ewald y Alessandro Fontana, Fondo de Cultura Económica, México DF, 2000, p. 218. Énfasis del original. 
La ciudadanía como dispositivo biopolítico se inscribe dentro de las relaciones de poder, como una más de las formas de dominación que ejerce el poder soberano La relación de tensión constante entre los procesos de dominación y las prácticas de contestación fue abordada por Foucault en varios de sus escritos. Para el pensador francés el poder puede ser concebido como una relación de fuerza entre diferentes agentes sociales, que desarrollan su actividad bajo relaciones de poder desiguales. Se trata, por tanto, de una noción sociorelacional de la que emanan tanto diferentes técnicas de dominación, como diversas formas de resistencia que, en su conjunto, constituyen y producen subjetividades individuales. El poder, así concebido, no debe ser entendido como algo que se posee y en virtud del cual se puede dominar a aquellos sujetos que carecen de él, sino que es algo que está presente en todo el cuerpo social a través de relaciones dinámicas y circulares ${ }^{55}$.

Así, los individuos son al mismo tiempo el efecto o consecuencia de las relaciones de poder, y el vehículo a través del cual estas se desarrollan, es decir, son tanto portadores del poder, como objetos de poder. En la lectura de Foucault esto tiene una consecuencia clara, si las relaciones de poder se producen entre individuos con intereses contrapuestos, estas relaciones pueden devenir en relaciones de dominación o relaciones de resistencia en función de la correlación de fuerzas, es decir, "[I]a relación de poder y la rebeldía de la libertad no pueden, pues, separarse [...] de una relación que es al mismo tiempo de incitación recíproca y de lucha"56. De este modo, dominación y resistencia constituyen las relaciones de poder, siendo que el poder no puede ser derrocado y la resistencia no puede ser eliminada. Así, Foucault concluye, "en el corazón de las relaciones de poder y como condición permanente de su existencia, hay una "insumisión" [...], no hay una relación de poder sin resistencia, sin escapatoria o huida"57.

En relación con el fenómeno migratorio, comparto con Squire ${ }^{58}$ que un enfoque foucaultiano parte de la consideración de que la migración irregularizada es producida como tal a través de operaciones de poder. Así, si el discurso es una forma de poder -capaz de producir realidad social- la responsabilidad por la irregularidad es atribuida, desde los discursos dominantes del poder soberano, a los propios migrantes a través de su criminalización o es alejada de ellos mediante su victimización ${ }^{59}$. Del mismo modo, un enfoque foucaultiano de las luchas migrantes permite reconocer la capacidad creativa de las comunidades migrantes en resistencia a la hora de contestar las formas de subjetivación a las que son sometidas, así como la puesta en práctica de una multiplicidad de procesos de resistencia a las constituciones dominantes de las relaciones de poder ${ }^{60}$. Bajo esta mirada, la resistencia no es solo una forma de negación de la dominación, sino también una lucha por la construcción de discursos, nuevos sentidos y, en definitiva, por la transformación de las relaciones poder.

55 FOUCAULT, Michel, "Defender la sociedad...", op.cit., p.38.

${ }^{56}$ FOUCAULT, Michel, «El sujeto y el poder», Revista Mexicana de Sociología 50, no 3, 1988, 3-20, p. 16.

57 Ibídem, p. 19.

58 SQUIRE, Vicki, «Unauthorised migration beyond structure/agency? Acts, interventions, effects», Politics 37, no 3, 2017, pp. 254-72, p. 265.

59 BEJA HORTA, Ana P., Contested Citizenship: Immigration Politics and Grassroots Migrants' Organizations in Postcolonial Portugal, Center for Migration Studies, 2004, p.307.

${ }^{60}$ Ver STIERL, Maurice, «"No One Is Illegal!" Resistance and the Politics of Discomfort», Globalizations 9, no 3, 2012, 425-38, p. 428. 
La visión de Foucault sobre las dinámicas de poder y resistencia permite corregir o matizar algunas posiciones demasiado reduccionistas de la autonomía de las migraciones que anteponen sin matices la movilidad humana y la agencia migrante a la dominación del poder soberano, obviando que ambas forman parte de un todo que emana de dinámicas de poder-resistencia íntimamente interrelacionadas. Sin embargo, Foucault no se ocupa en sus escritos de cómo la acción política antagonista es llevada a cabo, ni de cómo aquellos que son dominados desarrollan los discursos contra hegemónicos. Siguiendo a Edward Said, Ana Paula Beja Horta señala que,

"Foucault's concept of resistance as being functionally dependent on power prevents him from engaging in an analysis of the dynamics of micro-struggles not so much from the point of view of power but rather from a resistance perspective"61.

Paradójicamente, es en este punto en el que el enfoque de la autonomía de las migraciones puede completar las lagunas que deja el trabajo de Foucault. La aproximación autonomista hace hincapié, precisamente, en las dinámicas micro de los procesos de lucha de la población migrante y en las expresiones de resistencia cotidiana, tanto como en expresiones de resistencia organizada más clásicas y perceptibles. De este modo, ambos enfoques se muestran complementarios, en tanto que al ponerlos en diálogo es posible ampliar los horizontes explicativos para las dinámicas de acción política migrante ${ }^{62}$.

El espectro micropolítico de la vida cotidiana está compuesto por espacios poco visibles en los que grupos marginalizados desarrollan diversas formas de lucha. Estas políticas invisibles o inperceptibles surgen de las prácticas cotidianas de migrantes en su interacción con los regímenes de fronteras y de integración y mantienen una relación de equilibrio con otras formas más visibles y organizadas de acción política ${ }^{63}$. De este modo, a través de una gran variedad de experiencias, las luchas migrantes poseen una doble dimensión. Según New KeywordsCollective ${ }^{64}$, el propio término indica, en primer lugar, la existencia de luchas más o menos organizadas que, de forma abierta, desafían o escapan a las políticas de movilidad o el espacio de ciudadanía. Y en segundo lugar, las luchas migrantes se componen de una serie de estrategias diarias de supervivencia, contestaciones y resistencias a través de las cuales se sitúan en el espacio público incluso si estas no se manifiestan como luchas "políticas".

Así, las formas visibles de lucha comprenden aquellas que buscan generar atención pública y la visibilización de los migrantes como sujetos políticos, entre las que encontramos la ocupación de iglesias y otros lugares públicos, las huelgas de hambre o los bloqueos contra las deportaciones. Solo en Europa encontramos diversos ejemplos como las luchas de los sans papiers de finales de los noventa en Francia o los encierros de sin papeles en España a

\footnotetext{
${ }^{61}$ BEJA HORTA, Ana P., Contested Citizenship..., op.cit. p. 307.

62 Un relato interesnate que pone en conversación diferentes visiones del ámbito de la Autonomía de la Migraciones, los Estudios Críticos de Ciudadanía y el enfoque foucaultiano, puede leerse en ATAÇ, Ilker, RYGIEL, Kim, y STIERL, Maurice, «Introduction: TheContentiousPolitics of Refugee and MigrantProtest and SolidarityMovements: RemakingCitizenshipfromtheMargins», CitizenshipStudies 20, nº 5, 2016, pp. 527-544.

63 Ibídem, p. 538.

${ }^{64}$ CASAS-CORTES, Maribel et al., «New Keywords: Migration and Borders»,Cultural Studies 29, n 1, 2014, 55-87, p. 80.
} 
principios de los $2000^{65}$.

Las formas invisibles, por el contrario, tienen lugar en espacios poco visibles -incluso en el ámbito privado- y están relacionadas con prácticas cotidianas de la vida diaria. Estas prácticas políticas cotidianas cuestionan el orden y las fronteras de los estados y suelen pasar desapercibidas a los regímenes dominantes de visibilidad ${ }^{66}$. Entre las formas más comunes es posible identificar el cruce clandestino de fronteras y el ejercicio cotidiano del derecho a la permanencia, sorteando los dispositivos de control propios del régimen de fronteras, en lo que suponen formas de (re)apropiación de la movilidad; pero también los matrimonios "por papeles", las redes informales de solidaridad o prácticas destinadas a burlar los dispositivos de control como la destrucción de pasaportes o el borrado de huellas dactilares. Algunos autores han denominado estas prácticas como imperceptible politics, que explican a través de sus objetivos y efectos:

"Their targets pertain to the specific social struggles and social conflicts in which they are located. Imperceptible politics changes sensibilities, it changes the immediate social realities of existence in these fields in ways that, after a certain point, become impossible to ignore"67.

Este tipo de acciones desafían las definiciones tradicionales de agencia, al afirmar el carácter político de las prácticas de los grupos marginados, que estas suelen negar ${ }^{68}$. Aunque estas luchas cotidianas no siempre son perceptibles y es difícil establecer relaciones de causa efecto entre los eventos que ocurren a este nivel y otros en el ámbito de gobierno nacional o internacional, sí permiten a los individuos cuestionar y rechazar los discursos que contribuyen a su subjetivación como sujetos irregulares ${ }^{69}$. De este modo, la realidad social de las comunidades marginadas e irregularizadas no solo se circunscribe a las relaciones de dominación que mantienen con el poder soberano, sino que desarrollan prácticas que suponen una expresión de agencia política y dan forma a estrategias de resistencia capaces de crear nuevos sentidos y configurar unas subjetividades no impuestas, libres de la pesada carga de la irregularidad. Son precisamente la habilidad para cuestionar las categorías y las subjetividades impuestas y su capacidad de resistencia, las que traen aparejadas el potencial de transformación de la realidad social que poseen las luchas migrantes. De hecho, es esta potencia transformadora la que hace que las prácticas políticas migrantes se constituyan como algo más que meros actos de resistencia, para convertirse en prácticas performativas para la creación de nuevas situaciones que permitan cambiar las condiciones de existencia.

${ }^{65}$ AIERBE, Peio M, "Sin Papeles: Límites Como Movimiento, Fuerza Como Agente de Cuestionamiento Del Concepto de Ciudadanía," en Las Luchas de Los Sin Papeles y La Extension de La Ciudadania. Perspectivas Críticas Desde Europa y Estados Unidos., ed. SUAREZ, Liliana, MACIA-PAREJA, Raquel y MORENO, Ángela, Madrid, Traficantes de Sueños, 2007, pp. 237-52.

${ }^{66}$ ATAÇ, Ilker et al., «Struggles of Migration as in-/visible PoliticsIntroduction», Movements. JournalfürkritischeMigrations- undGrenzregimeforschung 1, no 2, 2015, 1-18, p.6.

67 PAPADOPOULOS, Dimitris, STEPHENSON, Niamh, y TSIANOS, Vassilis, "Escape Routes...", op.cit., p. 75.

${ }^{68}$ Las definiciones convencionales de agencia a menudo tiende a obviar el carácter político de las acciones de los colectivos marginados, al considerar que lo político principalmente ocurre en el ámbito delo gubernamental o de lo público. Ver STRANGE, Michael, SQUIRE, Vicki, y LUNDBERG, Anna, «Irregular migration struggles and active subjects of trans-border politics: New research strategies for interrogating the agency of the marginalised», Politics 37, no 3, 2017, 243-53, p. 247.

${ }^{69}$ Ibídem, p. 249. 
Se trata de expresiones de antagonismo biopolítico con potencial de transformación, tanto de los contextos en los que se inscriben, como de las condiciones de vida de sus actores.

\section{De los encierros al top manta. Luchas organizadas y espacios de resistencia cotidianas}

Durante los últimos veinticinco años se ha producido un aumento de las luchas migrantes en el espacio europeo. Según Lorenzo Cachón. ${ }^{70}$ vivimos "una fase de conflictos ligados a la inmigración porque entramos en el momento en que la "cuestión migratoria" y la "cuestión de la ciudadanía" confluyen. En que aquella no se entiende sin ésta y ésta viene problematizada por aquella". Sin embargo la falta de un reconocimiento formal de derechos en la vida cotidiana ha dado lugar a diferentes conflictos y luchas migrantes ${ }^{71}$. Desde la creación de los primeros colectivos de sin papeles en la década de los noventa, hasta la inauguración de una "nueva era de protesta" vinculada a las luchas de refugiados y solicitantes de asilo durante los últimos años" ${ }^{72}$ las movilizaciones migrantes han ganado en vigor y dinamismo, ejerciendo de facto el derecho a la movilidad y exponiendo las contradicciones del régimen de fronteras europeo. Unas contradicciones que, espoleadas por la propia crisis de Europa, están en el origen de la aparición de nuevas subjetividades migrantes. La participación en movilizaciones ha servido, en muchos casos, como elemento de politización de migrantes, facilitada por el empoderamiento que supone formar parte de procesos de organización y lucha colectivos y el acceso a redes sociales y políticas.

Una de las movilzaciones que constituyó un momento fundacional en este ciclo de luchas fue la de los sans papiers en Paris. El 18 de marzo de 1996, en un contexto de precariedad absoluta y hostigamiento, algo más de trescientos migrantes africanos se encierran en la Iglesia de Saint Ambroise. El encierro transitó por diferentes espacios y les llevó a emprender otras acciones más contundentes, como una huelga de hambre de casi tres semanas en la que participaron cincuenta y cuatro hombres y catorce mujeres ${ }^{73}$. Entre sus objetivos además de reclamar la regularización de su situación y la paralización de las deportacionesestaba el de rechazar públicamente la condición de ilegalidad, impuesta sobre ellos, a pesar de que en muchos casos habían residido en el país durante largos periodos y, al mismo tiempo buscar una interlocución que hasta entonces les había sido negada. Uno de sus portavoces, AbabacarDiop, lo explicaba de esta manera,

"We wanted to remind people that we existed and wished to be free of the illegality that French laws had thrust upon us. There was something extraordinarily simple in this vision. We were humans confronted with

70 CACHÓN, Lorenzo, "Conflictos e Inmigración: Experiencias En Europa", Ayuntamiento de Madrid, Madrid, 2007, p. 455.

71 Para un repaso más exhaustivo de estas luchas puede consultarse la obra de Chacón referenciada en la nota a pie de página anterior o .SUÁREZ-NAVAZ, Liliana, MACIA-PAREJA, Raquel, y MORENO GARCÍA, Ángela, Las Luchas de Los Sin Papeles y La Extensión de La Ciudadanía. Perspectivas Críticas Desde Europa y Estados Unidos, Madrid, Traficantes de Sueños, 2007.

72 Esta expresión se utiliza en un manifiesto llamando a la participación en Theprotestmarchproject. Disponible en http://www.refugeetentaction.net/index.php?option=com_content\&view=article\&id=42:a-call-to-join-theprotest-march-project-to-berlin-routes\&catid=19:about\&Itemid=161\&lang=en [Consultado el 14 de marzo de 2018]

73 GINER, Elena, "Los colectivos de sin papeles en Francia: Agentes de redefinición identitaria y ejercicio de ciudadanía local", en Las luchas de los sin papeles y la extension de la ciudadania. Perspectivas críticas desde Europa y Estados Unidos., ed. Liliana Suarez, Raquel Macia-Pareja, y Ángela Moreno García, Traficantes de Sueños, 2007, 73-103, p. 77. 
immense difficulties. What could be more natural than to make known our distress and to ask for a framework of negotiation with the authorities so that we could see an end to the tunnel, without animosity?"74.

Una de las características fundamentales de la lucha de los sans papiers es el papel autónomo que jugaron los propios migrantes a lo largo de todo el proceso de lucha. Madjiguène Cissé, otra de sus portavoces, asegura que,

"La lucha nos ha enseñado muchísimas cosas. Nos enseñó en principio a ser autónomos. Ello nunca ha sido sencillo. Hubo asociaciones que vinieron para apoyarnos pues tenían la costumbre de ayudar a los inmigrantes en lucha. Ellas tenían también la costumbre de hacer el vínculo entre los inmigrantes en lucha y los poderes públicos y, de hecho, de dirigir más o menos la lucha"m5.

Otra de las características definitorias de esta lucha está en la paradoja que supone el hecho de reivindicar derechos de ciudadanía al mismo tiempo que cuestionaban la ciudadanía como dispositivo de gobierno y control. De acuerdo con Imogen Tyler y KatarzynaMarciniak, "[t]he Sans-Papiers movement began as a struggle by undocumented workers in France for papers and regularization, but it became a movement that more radically questioned the neocolonial function of citizenship itself ${ }^{\prime \prime 76}$.

El movimiento de los sans papiers ha tenido una considerable influencia en muchas otras experiencias de activismo migrante que se han venido desarrollando durante las dos últimas décadas ${ }^{77}$; luchas contra el régimen de control de fronteras, contra las deportaciones o por la derogación de leyes de extranjería han seguido su estela en todo el espacio europeo. Un buen ejemplo de esta herencia lo encontramos en la Marcha por la Libertad de 2014, con destino a Bruselas y cuyo objetivo era reunir diferentes luchas migrantes del espacio europeo. Al hacerlo atravesando diferentes fronteras internas europeas con activistas provenientes de distintos países de la UE conseguían además dotar de un carácter transnacional a su lucha, lo que contribuye a trascender el estado-nación como gestor único de los derechos de ciudadanía y dibujar nuevos horizontes de pertenencia. Su manifiesto expresa claramente el rechazo a la ciudadanía y la frontera como mecanismos de diferenciación, pero también la firme determinación de ejercer la ciudadanía en la práctica y (re)apropiarse del derecho a la movilidad inherente a cualquier ser humano:

"We are asylum seekers, refugees, undocumented migrants, migrants from many European countries, we are Europeans with a "migration background", we are all those who have no full privilege of citizenship, but also citizens who share a common anger against the racist EU migration policy. [...] Showing that we don't respect the borders they impose us, holding us prisoners of the

\footnotetext{
74 DIOP, Ababacar, Thestruggle of the 'sans-papiers': realities and perspectives, 1997, Disponible en http://www. bok.net/pajol/sanspap/sptextes/ababacar2.en.html [Consultado el 14 de marzo de 2018]

75 CISSË, Madjiguène, Los Sin Papeles : Primeras enseñanzas, 1997, Original en francés en Politique, la revue, n02, 1996. Disponible en http://www.bok.net/pajol/madjiguene2.es.html [Consultado el 14 de marzo de 2018]

76 TYLER, Imogen y MARCINIAK, Katarzyna, «Immigrant protest...», op.cit., p. 147.

77 Ibídem, p. 147; AIERBE, Peio M, "Sin Papeles...", op.cit., p. 240.
} 
states borders and in the lagers, we will exercise our basic right of freedom of movement and address our demands directly where the decision come from"78.

Del mismo modo, la lucha de los sanspapiers ha inspirado al enfoque de la autonomía de las migraciones, al reunir varios de los supuestos que animan esta corriente: la primacía de las voces y las subjetividades migrantes sobre las tendencias a la mediación de otros actores sociales, el rechazo a la caracterización de víctimas o criminales, el cuestionamiento de la ciudadanía como dispositivo de control y exclusión, a la vez que se practica otra ciudadanía "clandestina" sin esperar a la obtención de un estatus legal, etc ${ }^{79}$.

Esta movilización, al igual que otras que surgieron en España ${ }^{80}$ y otros países europeos en los años posteriores ${ }^{81}$, reflejan una dimensión eminentemente organizada y visible de las luchas migrantes, pero los movimientos que están detrás de estas manifestaciones de activismo migrante se sustancian también en el día a día, en la creación de espacios de socialización y empoderamiento, espacios de creación de subjetividad a través de la revalorización y la puesta en común de toda una serie de saberes que son fundamentales a la hora de apropiarse de las posibilidades de movilidad y permanencia que faciliten unas condiciones de vida dignas.

Más recientemente, las luchas de los manteros en España han mostrado cómo una dimensión organizada y visible de la movilización, que incluye campañas por la despenalización de la venta ambulante y contra el racismo institucional, y su articulación a través de estructuras más o menos formales - como son los Sindicatos de manteros de Madrid y Barcelona ${ }^{82}$ - confluyen con otro tipo de estrategias de resistencia cotidiana que plantean una ocupación estratégica del espacio público desde el anonimato y la invisibilidad como estrategia de subsistencia, que a su vez, "tiene[n] el poder de transformar estructuras tan visibles, institucionalizadas y sistematizadas como el diseño de una ciudad y su urbanismo" ${ }^{\prime \prime}$.

Uno de los portavoces del Sindicato de vendedores ambulantes de Barcelona, AzizFaye ${ }^{84}$ cuando habla de sus prácticas políticas cotidianas destaca que su objetivo es "que

78 Eninglés, Protest March for Freedom. El manifiesto está disponible en línea en https://freedomnotfrontex. noblogs.org/files/2014/04/English1.pdf [Consultado el 15 de marzo de 2018]

79 TYLER, Imogen y MARCINIAK, Katarzyna, «Immigrantprotest...», op.cit., p. 147; MEZZADRA, Sandro, «Capitalismo, migraciones...», op.cit., p. 176.

80 Véase SUÁREZ-NAVAZ, Liliana, MACIA-PAREJA, Raquel, y MORENO GARCÍA, Ángela, «El Estado y las luchas de los sin papeles en España: ¿una extensión de la ciudadanía?», en Las luchas de los sin papeles y la extension de la ciudadania. Perspectivas críticas desde Europa y Estados Unidos., ed. Liliana Suarez, Raquel Macia-Pareja, y Ángela Moreno García, Traficantes de Sueños, 2007, 185-213.

${ }^{81}$ Sirvan como ejemplo las movilizaciones impulsadas por la red EuropeanNoBorders Network o el movimiento No OneisIllegal. Ver ATAÇ, Ilker et al., "Struggles of Migration...", op.cit., pp. 7-9; STIERL, Maurice, "No OneIsIllegal...", op.cit. pp. 434-437; y TYLER, Imogen y MARCINIAK, Katarzyna, «Immigrantprotest...», op.cit., p. 144.

82 El Sindicato popular de Vendedores Ambulante de Barcelona es un buen ejemplo. Su página web proporciona información sobre su misión y actividades, http://manteros.org. [Última consulta el 16 de marzo de 2018]

${ }^{83}$ ESPINOSA ZEPEDA, Horacio, "El Mercadillo Rebelde de Barcelona. Prácticas Antidisciplinarias En La Ciudad Mercancía," Quaderns de I'InstitutCatalad'Antropologia 22, nº 1, 2017, pp. 67-87.

${ }^{84}$ Véase IBORRA, Yeray. S., "Local propio, talleres y libros: la vida de los manteros más allá de las aceras", en eldiario.es, 15 de septiembre de 2017: https://www.eldiario.es/catalunya/barcelona/Local-talleres-inviernovendedores-ambulantes_0_686632242.html [Consultado el 22 de agosto de 2018] 
quede nuestra esencia en la ciudad. Para los muchos que vendrán [...]. Queremos ahondar en nuestras raíces: explicar de dónde venimos y dejar parte de nosotros en Barcelona, que ahora también es nuestra casa". En sus palabras, queda reflejada la (in)visibilidad estratégica, manifiesta en una búsqueda constante de la visibilidad de las problemáticas asociadas a la ilegalidad, la precariedad o el racismo.

Al mismo tiempo, los manteros - migrantes con y sin papeles- desarrollan estrategias de supervivencia que escapan a la visibilidad de control, en tanto que amenaza permanente para su propia existencia como migrantes irregularizados. Un ejemplo está representado en los esfuerzos por sortear las construcciones, las representaciones y los discursos que, a través de la visibilidad mediática, crean imágenes distorsionadas, fragmentadas y aisladas de su contexto. Iniciativas de comunicación directa con la sociedad, no mediada por instituciones o medios de comunicación, como pueden ser charlas en centros educativos ${ }^{85}$, son buena muestra de ello. Del mismo modo, la creación de una marca propia ${ }^{86}$ como mecanismo de representación simbólica y dignificación de su actividad es otra fórmula que conjuga construcción de subjetividad, autonomía y autorrepresentación. Esta, llamada icónicamente Top Manta, fue financiada a través de una campaña de micromecenazgo, en la que parte del dinero recaudado irá destinado a la asistencia legal o en materia de vivienda o salud de migrantes irregularizados o cuyas practicasde subsistencia están insertas en una lógica informal y precaria del mercado de trabajo, así como a proyectos educativos. De este modo, enlazan autonomía y prácticas políticas de resistencia con construcción de subjetividad y formas de autorrepresentación que trascienden la lógica institucional, creando una forma de visibilidad propia, más allá del foco mediático y el control del estado.

Si algo demuestran estas prácticas es que hacerse visible o situarse en espacios imperceptibles son prácticas complementarias, además de estrategias de resistencia orientadas, no solo a reclamar un lugar en la esfera pública, sino a transformarla a través de sus acciones ${ }^{87}$. Detrás de este potencial transformador está el objetivo de crear espacios donde las dinámicas de resistencia y las ciudadanías clandestinas puedan construir condiciones de existencia que permitan a las personas migrantes desplazarse allá donde quieran o necesiten, así como permanecer en condiciones dignas en el lugar de residencia elegido.

\section{Conclusión}

Este artículo ha planteado los procesos de resistencia migrante desde una perspectiva dual, que incluye una dimensión organizada que busca visibilizar los conflictos de las personas migrantes y darles voz y capacidad de (auto)representación; y otra basada en las experiencias cotidianas, muchas veces imperceptibles, pero que en su práctica diaria buscan garantizar las condiciones de posibilidad para una existencia digna. Mediando entre estas dos dimensiones de las luchas migrantes se encuentra una relación estratégica con la (in)visibilidad de los propios

${ }^{85}$ Véase IBORRA, Yeray. S., "Luchar contra el racismo desde la base: los manteros explican su experiencia a los jóvenes", en Cataluya Plural, 18 de febrero de 2018: http://catalunyaplural.cat/es/luchar-contra-racismo-desdebase-los-manteros-explican-su-experiencia-los-jovenes/ [Consultado el 16 de marzo de 2018]

${ }^{86}$ Véase IBORRA, Yeray. S., "Camisetas y zapatillas "Top manta": los vendedores ambulantes de Barcelona crean su propia marca", en eldiario.es, 5 de mayo de 2017: https://www.eldiario.es/catalunya/barcelona/Topvendedores-ambulantes-Barcelona-comercial_0_661434779.html [Consultado el 16 de marzo de 2018]

${ }^{87}$ TAZZIOLI, Martina y WALTERS, William, «The sight of migration: Governmentality, Visibility and Europe's contested borders», Global Society 30, n 3, 2016, pp. 445-64, p. 452. 
migrantes en sus prácticas y experiencias, que juega un papel clave en la configuración de una ciudadanía clandestina, concebida como práctica situada para la (re)apropiación de los derechos de movilidad y permanencia.

Es este un modelo de ciudadanía que choca con la noción más legalista y normativa que, en su relación diaria con las personas migrantes, funciona como dispositivo de control y diferenciación, en definitiva, una forma de gobierno de las poblaciones que junto con las fronteras y la proliferación de zonas de frontera en el interior de nuestras sociedades, dan forma a espacios en disputa en los que se establece una tensión permanente entre poder soberano y resistencia migrante. Para superar los obstáculos que impone el régimen migratorio y mirar más allá del horizonte de ciudadanía, las personas migrantes ponen en circulación un caudal creativo que, a través de conexiones sociales y personales, genera un cuerpo de conocimiento e información que supone un recurso común y compartido que algunos han denominado como mobile commons ${ }^{88}$. Estos comunes móviles se materializan en la vida cotidiana y contribuyen a facilitar los movimientos migratorios y evadir el control de la movilidad mediante la extensión y la multiplicación de las propiedades que lo constituyen.

El derecho a la movilidad y a la permanencia que persiguen las personas migrantes no puede conseguirse únicamente mediante la obtención de derechos y la ciudadanía - por muy necesarios que puedan resultar para los migrantes en muchas ocasiones- sino cambiando las condiciones de existencia que permiten una vida digna y el ejercicio de estos derechos. Por eso, si antes hacía referencia a la forma en la que el poder soberano regula el derecho de la vida y la muerte, para concluir se podría sugerir que la máxima foucaultiana de "hacer vivir y dejar morir" como expresión de las modernas configuraciones del biopoder, mutaría bajo el peso de las prácticas de antagonismo biopolítico migrante, hacia un "desear vivir y dejar de morir", esto es, facilitar la vida y las condiciones de existencia y despolitizar la muerte que, por acción u omisión acecha a aquellas personas que desafían el régimen de fronteras europeo.

\section{Bibliografía}

AGAMBEN, Giorgio, Homo Sacer. El Poder Soberano y La Nuda Vida I, Pre-Textos, Valencia, 1998.

AIERBE, Peio M., "Sin Papeles: Límites Como Movimiento, Fuerza Como Agente de Cuestionamiento Del Concepto de Ciudadanía" en Las Luchas de Los Sin Papeles y La Extension de La Ciudadania. Perspectivas Críticas Desde Europa y Estados Unidos., Ed. SUAREZ, Liliana, MACIA-PAREJA, Raquel, y MORENO GARCÍA, Ángela, 237-52. Madrid: Traficantes de Sueños, 2007.

APARICIO WILHELMI, Marco, "Los Derechos Sociales de las personas inmigradas En España" en Revista de Estudios Socio-Jurídicos, no 9, 2007, pp. 54-74.

ARANGO, Joaquín, "Derechos Sociales, Ciudadanía e Integración" en Gemma Pinyol (ed.), Inmigración y Derechos de Ciudadanía, CIDOB, Barcelona, 2006.

ATAÇ, Ilker, KRON, Stefanie, SCHILLIGER, Sarah, SCHWIERTZ, Helge, y STIERL, Maurice, "Struggles of Migration as In-/Visible PoliticsIntroduction" en Movements. JournalFürKritischeMigrationsUndGrenzregimeforschung, Vol. 1, n० 2, 2015, pp. 1-18.

ATAÇ, Ilker, RYGIEL, Kim, y STIERL, Maurice, "Introduction: The Contentious Politics of Refugee and Migrant Protest and Solidarity Movements: Remaking Citizenship from the Margins", en CitizenshipStudies, Vol. 20, no 5, 2016, pp. 527-44. doi: 10.1080/13621025.2016.1182681.

AVALLONE, Gennaro, "Migraciones y Relaciones de Poder En La Agricultura Global Contemporánea:

88 Para una lectura más profunda sobre los comunes móviles véase PAPADOPOULOS, Dimitris y TSIANOS, Vassilis S., «Aftercitizenship...», op.cit. pp. 190-192. 
Entre Actualidad y Ruptura de La Herencia Colonial" en Relaciones Internacionales, n 36, 2007, pp. 73-92.

BEJA HORTA, Ana Paula, Contested Citizenship: Immigration Politics and Grassroots Migrants Organizations in Post-Colonial Portugal, Center for Migration Studies, 2004. https://books. google.pt/books?id=XWOOAAAACAAJ

BENHABIB, Seyla, "Borders, Boundaries, and Citizenship", en PS: Political Science \& Politics, Vol. 38, no 4, 2005, pp. 673-77. doi: 10.1017/S1049096505050328.

BOJADŽIJEV, Manuela, and KARAKAYALI, Serhat, "Recuperating the Sideshows of Capitalism: The Autonomy of Migration Today", E-Flux 17, 2010, pp. 1-9.

BOLAÑOS, Bernardo, Biopolítica y Migración. El Eslabón Perdido de La Globalización, Ediciones Acapulco, México DF, 2015.

BRIGHENTI, Andrea, "Visibility" en Current Sociology, Vol. 55, no 3, 2007, pp. 323-42. doi: $10.1177 / 0011392107076079$.

CACHÓN, Lorenzo, "Conflictos e Inmigración: Experiencias En Europa", Ayuntamiento de Madrid, Madrid, 2007. doi: 10.15713/ins.mmj.3.

CASAS-CORTES, Maribel, COBARRUBIAS, Sebastian, DE GENOVA, Nicholas, GARELLI, Glenda, GRAPPI, Giorgio, HELLER, Charles, HESS, Sabine, et al., "New Keywords: Migration and Borders" en Cultural Studies, Vol. 29, no 1, 2015, pp. 55-87. doi: 10.1080/09502386.2014.891630.

CHAUVIN, Sébastien, y GARCÉS-MASCAREÑAS, Blanca, "Beyond Informal Citizenship: The New Moral Economy of Migrant Illegality" en International Political Sociology, Vol. 6, no 3, 2012, pp. 24159. doi: 10.1111/j.1749-5687.2012.00162.x.

CISSË, Madjiguène, «Los Sin Papeles : Primeras enseñanzas», 1997, Original en francés en Politique, la revue, no 2, 1996: http://www.bok.net/pajol/madjiguene2.es.html [Consultado el 14 de marzo de 2018]

DIOP, Ababacar, The struggle of the 'sans-papiers': realities and perspectives, 1997: http://www.bok. net/pajol/sanspap/sptextes/ababacar2.en.html [Consultado el 14 de marzo de 2018]

DÜVELL, Franck, "Paths into Irregularity: The Legal and Political Construction of Irregular Migration" en European Journal of Migration and Law, Vol. 13, no 3, 2011, pp. 275-95. doi: $10.1163 / 157181611 \times 587856$.

ECHEVERRÍA, Gabriel. "Living at the Margins of State: Ecuadorian Irregular Migrants in Amsterdam and Madrid.",Tesis Doctoral, Universidad Complutense de Madrid, Madrid, 2016.

ESPINOSA ZEPEDA, Horacio, "El Mercadillo Rebelde de Barcelona. Prácticas Antidisciplinarias En La Ciudad Mercancía," Quaderns de I'InstitutCatalad'Antropologia 22, no 1, 2017, pp. 67-87.

EUROSTAT, Migration and MigrationPopulationStatistics, 2017: http://ec.europa.eu/eurostat/statisticsexplained/index.php/Migration_and_migrant_population_statistics [Consultado el 11 de marzo de 2018]

FARGUES, Philippe, "Four Decades of Cross-Mediterranean Undocumented Migration to Europe", en Geneva, 2017.

FOUCAULT, Michel, Defender La Sociedad. Curso En El College de France (1975-1976). Editado por Françoise Ewald y Alessandro Fontana, Fondo de Cultura Económica, México DF, 2000. doi: 10.1017/CBO9781107415324.004.

FOUCAULT, Michel, «El sujeto y el poder», en Revista Mexicana de Sociología 50, n 3, 1988, pp. 3-20.

FOUCAULT, Michel, «The rights and duties of international citizenship», Open Democracy, 2015: https://www.opendemocracy.net/can-europe-make-it/michel-foucault/rights-and-duties-ofinternational-citizenship [Consultado el 10 de marzo de 2018]

FOUCAULT, Michel, Vigilar y castigar. Nacimiento de la prisión, Siglo XXI, Buenos Aires, 2002.

FUKUYAMA, Francis, "Identity, immigration, and liberal democracy" en Journal of democracy, Vol. 17, no 2, 2006, pp. 5-20.

GINER, Elena, "Los colectivos de sin papeles en Francia: Agentes de redefinición identitaria y ejercicio de ciudadanía local", en SUÁREZ, Liliana, MACIA-PAREJA, Raquel, y MORENO GARCÍA, Ángela (eds. ), Las luchas de los sin papeles y la extension de la ciudadania. Perspectivas críticas desde Europa y Estados Unidos, Traficantes de Sueños, Madrid, 2007, pp. 73-103.

GORDON, Colin, «The drowned and the saved: Foucault's texts on migration and solidarity», Open Democracy, 2015: https://www.opendemocracy.net/can-europe-make-it/colin-gordon/ drowned-and-saved-foucaults-texts-on-migration-and-solidarity [Consultado el 14 de marzo de 2018]

HUNTINGTON, Samuel P., "The Clash of Civilizations?" en Foreign Affairs, Vol. 72, no 3, 1993, pp. $22-49$. HYNDMAN, Jennifer, "The Geopolitics of Migration and Mobility" en Geopolitics, Vol. 17, no 2, 2012, pp. 243-55. doi: 10.1080/14650045.2011.569321.

IBORRA, Yeray. S., "Camisetas y zapatillas "Top manta": los vendedores ambulantes de Barcelona crean su propia marca", en eldiario.es, 5 de mayo de 2017: https://www.eldiario.es/catalunya/ barcelona/Top-vendedores-ambulantes-Barcelona-comercial_0_661434779.html [Consultado el 16 de marzo de 2018] 
IBORRA, Yeray. S., "Luchar contra el racismo desde la base: los manteros explican su experiencia a los jóvenes", en Cataluya Plural, 18 de febrero de 2018: http://catalunyaplural.cat/es/lucharcontra-racismo-desde-base-los-manteros-explican-su-experiencia-los-jovenes/ [Consultado el 16 de marzo de 2018]

KUBAL, Agnieszka, "Conceptualizing Semi-Legality in Migration Research" en Law and Society Review 47, no 3, 2013, pp. 555-87. doi:10.1111/lasr.12031.

LORI, Noora, "Statelessness, 'In-Between' Statuses, and Precarious Citizenship" en SHACHAR, Ayelet et al., The Oxford handbook of citizenship (ed.), Oxford University Press, 2017, pp. 743-767. doi: 10.1093/oxfordhb/9780198805854.013.32.

MEZZADRA, Sandro, "Capitalismo, Migraciones y Luchas Sociales: La Mirada de La Autonomía" en Nueva Sociedad, n²37, 2012, pp. 159-78.

NEW KEYWORDS COLLECTIVE, "Europe/Crisis: New Keywords of 'the Crisis' in and of 'Europe"' en Zone Books near Futures, 2016, 45.

NYERS, Peter. "Migrant Citizenships and Autonomous Mobilities" en Migration, Mobility, \& Displacement 1 , no 1, 2015. doi: 10.18357/mmd11201513521.

PAPADOPOULOS, Dimitris, and TSIANOS, Vassilis, "After Citizenship: Autonomy of Migration, Organisational Ontology and Mobile Commons" en Citizenship Studies, Vol. 17, no 2, 2013, pp. 178-96. doi: 10.1080/13621025.2013.780736.

PAPADOPOULOS, Dimitris, STEPHENSON, Niamh y TSIANOS, Vassilis, Escape Routes: Control and Subversion in the 21st Century, Londres, Pluto Press, 2008. doi: 10.1080/08935696.2012.685278.

PINYOL-JIMÉNEZ, Gemma, "The Migration-Security Nexus in Short: Instruments and Actions in the European Union", en Amsterdam Law Forum 4, no 1, 2011, pp. 36-57.

RIGO, Enrica, "Citizens despite Borders: Challenges to the Territorial Order of Europe", en The Contested Politics of Mobility: Borderzones and Irregularity, 2010, pp. 199-215. doi: 10.4324/9780203839829.

SAGER, Maja, "EverydayClandestinity: Experiences on the Margins of Citizenship and Migration Policies" en Lund University. Lund University, 2011. doi: 10.1177/0886109916651904.

SAMERS, Michael, "An Emerging Geopolitics of'Illegal' Immigration in the European Union" en European Journal of Migration and Law no 6, 2004, pp. 27-45. http://www.springerlink.com/index/ XQL1W1VNNY6R4LD1.pdf.

SAYAD, Abdelmalek, The suffering of the inmigrant, Cambridge, Polity, 2004.

SAYAD, Abdelmalek, "Estado, Nación e Inmigración. El Orden Nacional Ante El Desafío de La Inmigración" en Apuntes de Investigación Del CECYP, 2008, pp. 101-16.

SCHEEL, Stephan, "Studying Embodied Encounters: Autonomy of Migration beyond Its Romanticization" en Postcolonial Studies 16, no 3, 2013, pp. 279-88. doi:10.1080/13688790.2013.850046.

SCHEEL, Stephan, "Autonomy of Migration Despite Its Securitisation? Facing the Terms and Conditions of Biometric Rebordering." Millennium: Journal of International Studies 41, no 3, 2013, pp. 575-600. doi: 10.1177/0305829813484186.

SQUIRE, Vicki, "The Contested Politics of Mobility: Borderzones and Irregularity." The Contested Politics of Mobility: Borderzones and Irregularity, no diciembre, 2010, pp. 1-236. doi: 10.4324/9780203839829.

SQUIRE, Vicki, "Unauthorised Migration beyond Structure/Agency? Acts, Interventions, Effects" en Politics 37, no 3, 2017, pp. 254-72. doi: 10.1177/0263395716679674.

STIERL, Maurice. "'No One Is Illegal!' Resistance and the Politics of Discomfort" en Globalizations 9, no 3, 2012, pp. 425-38. doi:10.1080/14747731.2012.680738.

STRANGE, Michael, SQUIRE, Vicki, y LUNDBERG, Anna, "Irregular Migration Struggles and Active Subjects of Trans-Border Politics: New Research Strategies for Interrogating the Agency of the Marginalised." Politics 37, no 3, 2017, pp. 243-53. doi:10.1177/0263395717715856.

SUÁREZ-NAVAZ, Liliana, "Ciudadanía y Migración: ¿un Oximorón?" Revista de Migración, Puntos de Vista, no 4, 2005, pp. 29-47.

SUÁREZ-NAVAZ, Liliana, «Introducción. La lucha de los sin papeles. Anomalías democráticas y la (imparable) extensión de la ciudadanía», en SUAREZ, Liliana, MACIA-PAREJA, Raquel, y MORENO GARCÍA, Ángela (Ed.), Las luchas de los sin papeles y la extension de la ciudadania. Perspectivas críticas desde Europa y Estados Unidos, pp. 185-213, Traficantes de Sueños, 2007.

SUÁREZ-NAVAZ, Liliana, MACIA-PAREJA, Raquel y MORENO GARCÍA, Ángela, Las Luchas de Los Sin Papeles y La Extensión de La Ciudadanía. Perspectivas Críticas Desde Europa y Estados Unidos. Madrid, Traficantes de Sueños, 2007.

SUÁREZ-NAVAZ, Liliana, MACIA-PAREJA, Raquel, y MORENO GARCÍA, Ángela, "El Estado y Las Luchas de Los Sin Papeles En España: ¿una Extensión de La Ciudadanía?" en SUAREZ, Liliana, MACIAPAREJA, Raquel, y MORENO GARCÍA, Ángela (Ed.), Las Luchas de Los Sin Papeles y La Extension de La Ciudadania. Perspectivas Críticas Desde Europa y Estados Unidos, pp. 185-213, Traficantes de Sueños, 2007.

TAZZIOLI, Martina, y WALTERS, William, "The Sight of Migration: Governmentality, Visibility and Europe's 
Contested Borders." Global Society 30, n 3, 2016, pp. 445-64. doi:10.1080/13600826.2016. 1173018.

TURNER, Joe, "(En)Gendering the Political: Citizenship from Marginal Spaces", en Citizenship Studies 20, no 2, 2016, pp. 141-55. doi:10.1080/13621025.2015.1132569.

TYLER, Imogen, y MARCINIAK, Katarzyna, "Immigrant Protest: An Introduction", Citizenship Studies 17, n० 2 (2013): 143-56. doi:10.1080/13621025.2013.780728.

UNITED, The Fatal Policies of Fortress Europe, 2017: http://www.unitedagainstracism.org/ campaigns/ annual-campaigns/fortress-europe/ [Cosultado el 11 de marzo de 2018]

VARELA HUERTA, Amarela, "La ciudadanía instituida en la era de la resistencia: el movimiento migrante en Barcelona como agente de nuevos dircusos" en BOLAÑOS, Bernardo (Ed.), Biopolítica y Migración. El eslabón perdido de la globalización, pp. 261-308, México DF, Ediciones Acapulco. 2015.

VILLEGAS, Francisco J., "CHAPTER SEVEN : Strategic In / Visibility and Undocumented Migrants", Counterpoints 368, 2010, pp. 147-70.

WEINER, Myron, "Security, Stability, and International Migration", International Security, Vol. 17, no 3, 1992, pp. 91-126. 


\section{RELACIONES INTERNACIONALES}

Revista académica cuatrimestral de publicación electrónica Grupo de Estudios de Relaciones Internacionales (GERI) Universidad Autónoma de Madrid, España

www.relacionesinternacionales.info

ISSN 1699 - 3950

ff facebook.com/RelacionesInternacionales

twitter.com/RRInternacional 